the marked decrease in damage over time and the more pronounced decline in the Biologic era (Figure 1).

Conclusion: Our study provides evidence of the remarkable prognostic improvement obtained with the recent therapeutic advance in JIA.

REFERENCES:

[1] Solari et al. Arthritis Care Res. 2008;59:1571-9.

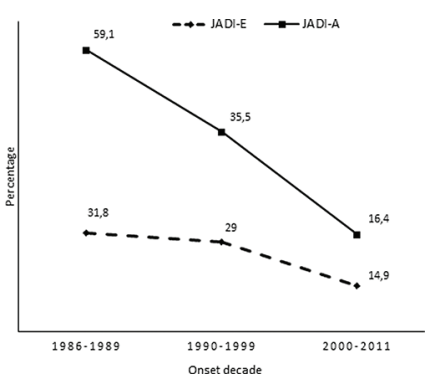

Figure 1. Trend in disease damage throughout methotrexate and biologic era.

Disclosure of Interests: Gabriella Giancane: None declared, Valentina Muratore: None declared, Valentina Marzetti: None declared, Neus Quilis Marti: None declared, Belén Serrano Benavente: None declared, Francesca Bagnasco: None declared, Alessandra Alongi: None declared, Adele Civino: None declared, Lorenzo Quartulli: None declared, Alessandro Consolaro Grant/research support from: AbbVie, Pfizer, Angelo Ravelli Grant/ research support from: Angelini, AbbVie, Bristol-Myers Squibb, Johnson \& Johnson, Novartis, Pfizer, Reckitt Benkiser, and Roche, Consultant for: Angelini, AbbVie, Bristol-Myers Squibb, Johnson \& Johnson, Novartis, Pfizer, Reckitt Benkiser, and Roche, Speakers bureau: Angelini, AbbVie, Bristol-Myers Squibb, Johnson \& Johnson, Novartis, Pfizer, Reckitt Benkiser, and Roche

DOI: 10.1136/annrheumdis-2019-eular.5488

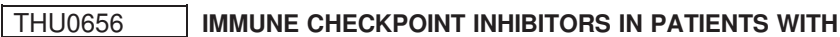 CANCER AND RHEUMATOLOGIC DISEASES: A SYSTEMATIC REVIEW OF THE LITERATURE}

Noha Abdel-Wahab ${ }^{1,2}$, Houssein Safa ${ }^{3}$, Maria A. Lopez-Olivo ${ }^{4}$, Adi Diab ${ }^{3}$, Maria Suarez-Almazor ${ }^{4} .{ }^{1}$ University of Texas MD Anderson Cancer Center, Section of Rheumatology and Clinical Immunology, houston, United States of America; ${ }^{2}$ Faculty of Medicine, Assiut University Hospital, Department of Rheumatology and Rehabilitation, Assiut, Egypt, ${ }^{3}$ University of Texas MD Anderson Cancer Center, Melanoma Medical Oncology, houston, United States of America; ${ }^{1}$ University of Texas MD Anderson Cancer Center, Section of Rheumatology and Clinical Immunology, houston, United States of America

Background: Immune checkpoint inhibitors (ICI) have resulted in unprecedented advances in the treatment of cancer, with remarkable survival benefits, unseen with traditional treatment. While the benefits of $\mathrm{ICl}$ have been clearly documented, a myriad of immune-related-adverse events (irAEs) have been recognized in multiple organs and systems, secondary to persistent activation of the immune system.

Objectives: To systematically review the literature and provide an updated summary on adverse events associated with the use of $\mathrm{ICl}$ therapy in patients with cancer and rheumatologic diseases.

Methods: Five electronic databases were searched through 2018 with no restrictions. Articles were screened and selected by two independent investigators using a 2-step approach. Case reports, series, and observational studies describing patients diagnosed with rheumatologic disease prior to initiation of $\mathrm{ICl}$ for treatment of concomitant cancer were included.

Results: A total of 69 patients in 27 publications were identified. Median age was 65 (38-87) years; $50 \%$ were female; $90 \%$ had metastatic melanoma; and $64 \%$ were receiving anti-cytotoxic T-lymphocyte-associated protein 4 (anti-CTLA-4) antibody. Rheumatoid arthritis was the most common in $64 \%(n=32)$. Other rheumatologic diseases included 16 spondyloarthropathy (7 psoriatic arthritis, 4 ankylosing spondylitis, 1 reactive arthritis, and 4 unspecified), 8 sarcoidosis, 6 vasculitis (3 eosinophilic granulomatosis with polyangiitis, and 1 each with granulomatosis with polyangiitis, Behcet's diseases, and polymyalgia rheumatica), 2 each with systemic lupus erythematosus and scleroderma, and 1 each with rheumatic fever, Sjögren's syndrome, and myositis. Overall, $73 \%(n=50)$ had an adverse event after initiation of $\mathrm{ICl}$; $33 \% \quad(n=32)$ had an exacerbation of the underlying disease, and $55 \% \quad(n=38)$ had de novo irAEs. Patients with active diseases at $\mathrm{ICl}$ initiation seemed to have more disease flare than those with inactive disease $(61 \%$ vs. $29 \% ; p=0.03)$, while no differences were observed in de novo irAEs (36\% vs. $39 \%)$. Patients with rheumatoid arthritis were reported to have more flares with anti-CTLA-4 antibody $(63 \%$ vs. $33 \%)$, while those with spondyloarthropathy reported more flares with anti-programmed cell death 1 agents (63\% vs. $29 \%$ ); however numbers were small. Patients receiving immunosuppressive therapy at $\mathrm{ICl}$ initiation had fewer adverse events than those not receiving treatment $(26 \%$ vs. $44 \%)$. Most flares and irAEs were managed with corticosteroids, and $13 \%$ required additional disease modifying anti-rheumatic drugs. Adverse events improved in $64 \%$ and did not require discontinuation of $\mathrm{ICl}$ therapy. In melanoma patients, disease control rate was $44 \%$. In all patients, no treatment related mortality was reported.

Conclusion: About one third of patients with pre-existing rheumatologic autoimmune disease flared after receiving $\mathrm{ICl}$ therapy for treatment of cancer. However, flares and irAEs can often be managed and may not require discontinuation of cancer therapy. Prospective longitudinal studies are needed to evaluate potential differences among diseases and to determine optimal toxicity therapy while conserving antitumor immunity. Disclosure of Interests: : None declared DOI: 10.1136/annrheumdis-2019-eular.6541

\section{THU0657 ASSOCIATION OF DIET AND SPICES WITH TREATMENT OUTCOME IN ASIAN INDIAN PATIENTS WITH RHEUMATOID ARTHRITIS - A CROSS SECTIONAL STUDY}

Harshini Alur Shivakumar ${ }^{1}$, Ramya Aithala ${ }^{1}, L_{\text {L Jeyaseelan }}^{2}$, Debashish Danda ${ }^{1}$.

${ }^{1}$ Christian Medical College, Clinical Immunology and Rheumatology, Vellore, India; ${ }^{2}$ Christian Medical College, Biostatistics, Vellore, India

Background: Influence of diet on inflammation, specially foods like fish oil, spices like turmeric, capsaicin, garlic etc. are reported in published literature. However, a well-designed study on this subject amongst Asian Indian patients is lacking.

Objectives: To analyze whether the type and quantity of intake of various food constituents, with particular reference to Indian spices, makes an impact on the control of disease activity in patients with Rheumatoid arthritis(RA)

Methods: Patients diagnosed as RA by the ACR 2010 criteria and receiving standard triple drug therapy in our clinic between June 2017 and June 2018, for at least one year were enrolled. Disease activity was assessed during the routine OPD visit. They were administered a food frequency questionnaire ${ }^{[1]}$ pertaining to the quality as well as quantity of food and spice intake. Analysis was done using multivariate logistic regression

Results: A total of 400 patients were included with $86.75 \%$ females. $67.75 \%$ patients were in disease remission, $10 \%$ had mild disease activity and $22.25 \%$ moderate to high disease activity; only $18.09 \%$ were vegetarians and the rest consumed non-vegetarian food. Median age was 47.99years(SD 10.67), median duration of illness prior to presentation to our clinic was 7years(IQR 4,10), median ESR was $37 \mathrm{~mm} / \mathrm{hr}(\mathrm{IQR} \quad 23,52)$, median CRP was5.34mg/L(IQR 2.04,12.4), and median DAS28CRP was 2.07(IQR 1.64,2.97). Patients with DAS28CRP of $<2.6$ were compared with those $>3.2$. Statistically higher consumption of ginger, garlic, turmeric and coriander were noted amongst patients in remission. Similar results were obtained when patients with DAS28CRP of $<1.4$ were compared with DAS28CRP $>5.1$. Nonsignificant numerical differences were noted for intake of food constituents like wheat, total pulse, vegetables, fruit, milk and fish

\begin{tabular}{lccccc}
\hline & DAS28CRP <2.6 & \multicolumn{3}{c}{$\begin{array}{c}\text { DAS28CRP }> \\
3.2\end{array}$} \\
\hline $\begin{array}{l}\text { Dietary } \\
\text { items }\end{array}$ & $\mathrm{n}$ & $\begin{array}{c}\text { Quantity in grams Median } \\
\text { (IQR) }\end{array}$ & $\mathrm{n}$ & $\begin{array}{c}\text { Quantity in } \\
\text { grams }\end{array}$ & $\begin{array}{c}\mathrm{P} \\
\text { value }\end{array}$ \\
ginger & 244 & $4.17(2.67,6.67)$ & 80 & $2.08(1.39,3.33)$ & 0.0001 \\
garlic & 253 & $4.17(2,78,6.67)$ & 78 & $2.08(1.67,3.33)$ & 0.0001 \\
turmeric & 267 & $1.11(0.71,1.67)$ & 88 & $0.83(0.51,1.11)$ & 0.0003 \\
jeera & 215 & $0.55(0.37,0.83)$ & 64 & $0.42(0.28,0.75)$ & 0.0138 \\
cinnamon & 64 & $0.42(0.28,0.55)$ & 24 & $0.35(0.25,0.52)$ & 0.7212 \\
cloves & 85 & $0.42(0.28,0.55)$ & 28 & $0.33(0.2,0.45)$ & 0.6754 \\
coriander & 230 & $1.11(0.67,1.67)$ & 78 & $0.67(0.48,1.11)$ & 0.0001 \\
pepper & 179 & $0.42(0.33,0.67)$ & 57 & $0.37(0.28,0.55)$ & 0.0351 \\
chilli & 259 & $2.08(1.67,3.33)$ & 88 & $1.67(1.02,2.82)$ & 0.0023 \\
\hline
\end{tabular}


Table 1. Comparison between patients in remission with those having moderate/high disease activity

\begin{tabular}{lcc}
\hline Variables & OR $(95 \% \mathrm{Cl})$ & $\begin{array}{c}\mathbf{P}- \\
\text { Value }\end{array}$ \\
\hline Ginger & $0.62(0.47$, & $<0.001$ \\
Garlic & $0.81)$ & $<0.001$ \\
& $0.61(0.46$, & \\
Turmeric & $0.79)$ & 0.01 \\
Jeera & $0.63(0.46$, & 0.13 \\
Coriander & $0.87)$ & \\
Pepper & $0.75(0.51$, & 0.01 \\
& $1.09)$ & 0.3 \\
Chilli & $0.59(0.41$, & \\
& $0.83)$ & 0.01 \\
\hline
\end{tabular}

Multivariate logistic regression for the statistically significant variables

Conclusion: Higher consumption of Indian spices like ginger, garlic, turmeric and coriander were found to be associated with better control of disease activity and hence the inflammation, as evidenced by DAS28CRP in patients with Rheumatoid arthritis, receiving standard triple therapy

\section{REFERENCES:}

[1] Shim JS, Oh K, Kim HC. Dietary assessment methods in epidemiologic studies. Epidemiol Health. 2014

Disclosure of Interests: None declared

DOI: 10.1136/annrheumdis-2019-eular.7327

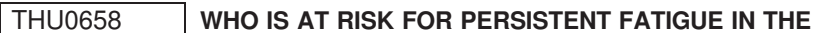 FIRST YEAR OF RA? CHARACTERISTICS OF PATIENTS WITH PERSISTENT FATIGUE IN THE FIRST YEAR BY SEX IN THE CANADIAN EARLY ARTHRITIS COHORT (CATCH)}

Susan J. Bartlett $^{1,2}$, Orit Schieir ${ }^{3}$, Marie-France Valois ${ }^{4}$, Janet Pope ${ }^{5}$, Louis Bessette $^{6}$, Carol Hitchon ${ }^{7}$, Carter Thorne ${ }^{8,9}$, Diane Tin ${ }^{8}$, Glen Hazlewood ${ }^{10}$, Gilles Boire ${ }^{11}$, Edward Keystone ${ }^{12}$, Vivian Bykerk ${ }^{13}$. $^{1}$ Mc Gill University, Center for Outcomes Research and Evaluation, Montréal, Canada; ${ }^{2}$ Johns Hopkins, Medicine, Baltimore, United States of America; ${ }^{3}$ University of Toronto, Toronto, Canada; ${ }^{4}$ McGill University, Montreal, Canada; ${ }^{5}$ Western University, London, Canada; ${ }^{6}$ Laval University, Quebec City, Canada; ${ }^{7}$ University of Manitoba, Winnipeg, Canada; ${ }^{8}$ Southlake Regional Health Center, Newmarket, Canada; ${ }^{8}$ Southlake Regional Health Center, Newmarket, Canada; ${ }^{10}$ University of Calgary, Calgary, Canada; ${ }^{11}$ University of Sherbrooke, Sherbrooke, Canada; ${ }^{12}$ Mt. Sinai Hospital, Toronto, Canada; ${ }^{13}$ Hospital for Special Surgery, Rheumatology, New York, United States of America

Background: While treat-to-target strategies can dramatically reduce RA inflammation, persistent fatigue is present in up to half of RA patients, and is an important unmet need. Proposed underlying causes include RA disease, cognitive/emotional/behavioral (CEB), and personal (health) factors.

Objectives: To identify risk factors for persistent fatigue at 12-months in men and women with ERA on immunomodulatory therapies.

Methods: Data were from patients enrolled in the Canadian Early Arthritis Cohort (CATCH) between 01-2007 and 03-2017 who met 1987 or 2010 ACR/EULAR RA criteria, had active disease treated with DMARDS, and had complete data on DAS28, BMI, and fatigue severity (0-10) over 12months. Persistent fatigue, was defined as fatigue $>4$ at baseline with $<20 \%$ improvement at 12 months. Multivariable logistic regression was used to identify RA disease, CEB, and personal/health factors associated with persistent fatigue.

Results: Patients were mostly white $(81 \%)$, female $(71 \%)$, with a mean (SD) age of 54 (15), symptom duration of 6 (3) months, and BMI of $28.0(6.1) ; 32 \%$ were obese $(\mathrm{BMI} \geq 30)$. Women were generally younger, better educated, seropositive, and had greater disability, fatigue, depressive symptoms, and major stress in the past year $(p<.05) .21 \%$ of women and $19 \%$ of men reported persistent fatigue.

\begin{tabular}{|c|c|c|c|}
\hline Mean (SD) or $\mathbf{N}(\%)$ & $\begin{array}{c}\text { Women } \\
\mathrm{N}=579\end{array}$ & $\begin{array}{c}\text { Men } \\
\mathrm{N}=208\end{array}$ & $P$ value \\
\hline Age & $52(15)$ & $59(13)$ & $<0.0001$ \\
\hline$>$ High School education & $\begin{array}{c}405 \\
(57 \%)\end{array}$ & $\begin{array}{c}134 \\
(47 \%)\end{array}$ & $<0.01$ \\
\hline \multicolumn{4}{|l|}{ RA Disease } \\
\hline Symptom duration (mnth) & $5.7(3.0)$ & $5.6(2.9)$ & 0.65 \\
\hline $\mathrm{RF}+$ or $\mathrm{ACPA}+$ & $\begin{array}{c}526 \\
(84 \%)\end{array}$ & $\begin{array}{c}177 \\
(75 \%)\end{array}$ & $<0.01$ \\
\hline DAS28 (MDA/HDA v. LDA/REM) & $\begin{array}{c}688 \\
(96 \%)\end{array}$ & $\begin{array}{c}272 \\
(94 \%)\end{array}$ & 0.17 \\
\hline Pain $(0-10)$ & $5.8(2.8)$ & $5.7(2.8)$ & 0.55 \\
\hline HAQ-DI & $1.1(0.7)$ & $1.0(0.7)$ & 0.02 \\
\hline \multicolumn{4}{|l|}{ Cognitive/Emotional/Behavioral (CEB) } \\
\hline Baseline fatigue $(0-10)$ & $5.6(3.0)$ & $4.9(2.9)$ & $<0.01$ \\
\hline Obese $(\mathrm{BMI} \geq 30)$ & $\begin{array}{c}223 \\
(31 \%)\end{array}$ & $93(32 \%)$ & 0.74 \\
\hline Current Smoking & $\begin{array}{c}110 \\
(15 \%)\end{array}$ & $54(19 \%)$ & 0.19 \\
\hline Depressive Symptoms (SF12 MCS & 356 & $92(35 \%)$ & $<0.0001$ \\
\hline$<45.6)$ & $(53 \%)$ & & \\
\hline Major stress past year & $\begin{array}{c}401 \\
(56 \%)\end{array}$ & $\begin{array}{c}123 \\
(43 \%)\end{array}$ & 0.0001 \\
\hline \multicolumn{4}{|l|}{ Personal/Health } \\
\hline Work (full/part time) & $\begin{array}{c}401 \\
(56 \%)\end{array}$ & $\begin{array}{c}149 \\
(52 \%)\end{array}$ & 0.20 \\
\hline Rheumatoid Disease Comorbidity Index & $1.1(1.3)$ & $1.3(1.3)$ & 0.06 \\
\hline OA or backpain & $\begin{array}{c}164 \\
(23 \%)\end{array}$ & $57(20 \%)$ & 0.27 \\
\hline Fibromyalgia & $20(3 \%)$ & $3(1 \%)$ & 0.09 \\
\hline Poor sleep & $5.2(3.2)$ & $5.0(3.3)$ & 0.41 \\
\hline
\end{tabular}

In multivariable regression that included all Table 1 variables, predictors of persistent fatigue in women were obesity (OR 1.7; 95\% Cl 1.1, 2.6), initial steroid use (OR 1.7; 95\% Cl 1.1, 2.7), seronegativity (OR 0.6; $95 \% \mathrm{Cl} 0.4,1.0)$ and poor sleep (OR 1.1; 95\% Cl 1.0, 1.2). Obesity was the only significant predictor in men and was assoicated with a 2.4 times higher odds $(95 \% \mathrm{Cl} 1.1,5.1)$ of persistent fatigue at $1 \mathrm{yr}$. Other sociodemographic, RA characteristic, CEB and personal/health factors were not associated with persistent fatigue in either sex in multivariable models.

Conclusion: Obesity is common in ERA and a major determinant of persistent fatigue in women and men. In obese RA patients on guidelinebased treatment, lifestyle interventions targeting weight loss may play an important role in reducing persistent fatigue that does not improve with RA treatment.

\section{REFERENCES: :}

Disclosure of Interests: : Susan J. Bartlett Consultant for: Pfizer, UCB, Lilly, Novartis, Merck, Jansen, Abbvie, Orit Schieir: None declared, Marie-France Valois: None declared, Janet Pope Consultant for: Eli Lilly and Company, Louis Bessette Grant/research support from: Amgen, BMS, Janssen, Roche, UCB, AbbVie, Pfizer, Merck, Celgene, Sanofi, Lilly, Novartis, Consultant for: Amgen, BMS, Janssen, Roche, UCB, AbbVie, Pfizer, Merck, Celgene, Sanofi, Lilly, Novar tis, Speakers bureau: Amgen, BMS, Janssen, Roche, UCB, AbbVie, Pfizer, Merck, Celgene, Sanofi, Lilly, Novartis, CArol Hitchon Grant/research support from: Pfizer, UCB (unrelated studies), Carter Thorne Grant/research support from: Investigator-initiated studies: Amgen, Pfizer. RCTs: Abbvie, Celgene, CaREBiodam, Novartis, Pfizer, Consultant for: Advisory board: Abbvie, Amgen Celgene, Lilly, Medexus/Medac, Merck, Novartis, Pfizer, Sanofi. Consultant: Abbvie, Centocor, Janssen, Lilly, Medexus/Medac, Pfizer, Speakers bureau: Medexus/Medac, Diane Tin: None declared, Glen Hazlewood: None declared, Gilles Boire Grant/research support from: Investigator-initiated studies: Amgen, Abbvie, BMS, Eli Lilly, Merck, Novartis, Pfizer, Consultant for: Advisory boards: Amgen, BMS, Celgene, Eli Lilly, Pfizer, Speakers bureau: Merck, BMS, Pfizer, Edward Keystone Grant/research support from: AbbVie, Amgen, Bristol-Myers Squibb, F. Hoffmann-La Roche Inc, Gilead, Janssen Inc, Lilly Pharmaceuticals, Pfizer Pharmaceuticals, Sanofi-Aventis, Consultant for: AbbVie, Amgen, AstraZeneca Pharma, Biotest, Bristol-Myers Squibb Company, Celltrion, Crescendo Bioscience, F. Hoffmann-La Roche Inc, Genentech Inc, Gilead, Janssen Inc, Lilly Pharmaceuticals, Merck, Pfizer Pharmaceuticals, Sandoz, UCB., Speakers bureau: Amgen, AbbVie, Bristol-Myers Squibb Canada, F. Hoffmann-La Roche Inc., Janssen Inc., Merck, Pfizer Pharmaceuticals, Sanofi Genzyme, UCB, Vivian Bykerk Grant/research support from: Mallinckrodt, BMS, Crescendo Biosciences, Sanofi/Regeneron., Consultant for: Amgen, Pfizer, UCB, Scipher, Sanofi/Genzyme/Regeneron

DOI: 10.1136/annrheumdis-2019-eular.6356 